\title{
Professional Portfolios for Health Educators and Other Allied Health Professionals
}

\author{
Sharon E. Thompson and Ronald F. Bybee \\ The University of Texas at El Paso
}

\begin{abstract}
A professional portfolio is a compilation of material that documents a health educator's competencies. A portfolio can assist students relate academic assignments to the practical skills that are necessary for the practicing health educator (Waishwell, Morrow, Micke \& Keyser, 1996). The portfolio should be conceptualized as a "living document" that is ever-changing with the increasing depth of knowledge and experience of the individual. During a Society for Public Health Education/American Association for Health Education Program Approval Process (SABPAC) visit, the site team recommended that students develop a portfolio as an assignment in an introductory health education course. By instituting this assignment earlier in their academic careers, students become oriented to the process of collecting and organizing assignments and material for their portfolio, as well as documenting volunteer experiences and/or health education in the community. This portfolio can eventually be used as a job-seeking instrument that gives potential employers an overview of an applicant's strengths and experiences.
\end{abstract}

(C) 2004 Californian Journal of Health Promotion. All rights reserved.

Keywords: professional portfolio, health education, professional preparation, students

\section{Definitions}

Traditionally, engineers and artists have utilized professional portfolios. However, other fields now recognize the benefits of portfolios and incorporated the development of one as part of a student's training (Benitez, 2003). A portfolio is defined as "a collection of evidence that enables students to demonstrate mastery of desired course or program outcomes" (Cottrell, Girvan, McKenzie, 2002, p. 337). Michael J. Cleary (1993) asserted that a portfolio is a "repository that enables students to document authentic examples of academic work and presentations as well as non-school accomplishments” (p. 377). Portfolios are "purposeful and selective collections of authentic evidence regarding teaching and learning (Cleary \& Birch, 1997).

In a health education program, a portfolio can be utilized to assist students relate academic assignments to the practical skills that are necessary for the practicing health educator (Waishwell, Morrow, Micke \& Keyser, 1996). It is recommended that the Responsibilities and Competencies of an Entry Level Health Educator be emphasized in a health education student's portfolio (Cottrell et al., 2002; Waishwell et al., 1996). In addition, student portfolios have been used as an outcome-based performance assessment tool in various health education courses (Cleary \& Birch, 1996).

\section{Purpose}

There are various types of portfolios. These types include "best work" and "growth and development” (Gaberson \& Oermann, 1999; Grant \& Huebner, 1998; Oermann, 2002). In addition, professional portfolios can be used in the hiring process, retention, evaluation and/or promotion, as well as an outcome-based assessment (Cleary, \& Birch, 1996; Salend, 2000). A professional portfolio can serve as an extension of a resume and can be utilized to document the scope and quality of one's experience and training while presenting tangible proof of one's skills and experiences (Wurdeman, 2002).

\section{Elements}

The portfolio should be conceptualized as a "living document" that is ever- changing with the increasing depth of knowledge and 
experience of the individual. However, there are basic elements of a professional health education portfolio that even a student completing an introductory course in health education should be able to compile. These basic elements include: 1) a table of contents, 2) resume, 3) education and credentials, 4) samples of work, and 5) references. As the student advances through his/her academic career additional sections that may be included are: philosophy of health education, awards and honors, continuing education and training, and/or volunteer experience.

\section{Timing}

During the site visit for Society for Public Health Education/American Association for Health Education Program Approval (SABPAC) process, the Site Team recommended that the Health Science Program at The University of Texas at El Paso require students to develop a portfolio as an assignment in the Foundations of Health Science and Health Promotion course. Prior to that recommendation, the development of a professional portfolio was assigned in a senior-level health science course.

Students produce relevant papers and assignments throughout their academic careers that are appropriate for inclusion in a professional portfolio. In addition, students often have pertinent community health experiences through class projects and/or volunteerism. By instituting this assignment earlier in their academic careers, students become oriented to the process of collecting and organizing assignments and material for their portfolios, as well as documenting volunteer experiences and/or health education in the community.

\section{Instrument for an Interview}

A professional portfolio is a job-seeking instrument that gives potential employers an overview of an applicant's strengths and experiences (Wurdeman, 2002). It can be utilized during an interview to showcase various skills, strengths, abilities, experiences, and achievements (Benitez, 2003; Wurdeman, 2002). The portfolio can be a particularly useful tool for the neophyte interviewee. It is not unusual for a recent graduate to experience nervous energy during an interview. The portfolio can serve an instrument to help the interviewee organize his/her thoughts as well as elucidate various concepts and with examples of projects and experiences.

A portfolio can highlight one applicant over other. A recent graduate reported that, upon being hired, her new employer indicated that her portfolio was the deciding factor between another applicant and her (Benitez, 2003). The employer felt that the portfolio provided an opportunity to evaluate a visual representation of topics discussed during the course of the interview. It also represented the applicant's initiative and ability to organize. It is important to have copies of the portfolio contents should the interviewer wish review the material after the interview. It is not recommended to provide original copies.

\section{A Clinician's Perspective}

In the Physical Therapy Program at The University of Texas at El Paso, students are required to develop a Professional Practice Portfolio during their completion of an eight semester graduate curriculum. The assignment is given during the initial semester and completed by the end of the seventh semester. In the interim, the academic advisor and/or any professor may ask the student to submit the unfinished portfolio for review. This is intended to encourage the student to remain committed to the project by routinely updating the document. The portfolio is meant to be a collection of the students' work that documents learning experiences throughout the course of their physical therapy education. The overriding purposes are:

1. Facilitate learner participation in the learning process.

2. Emphasize the practicality of academic instruction.

3. Offer a secondary means to measure academic success.

In addition to the basic elements of a portfolio previously outlined, the students are encouraged to include a plan for personal and professional 
development, scholarships, grants, performance evaluations during the 30 weeks of clinical affiliations, patient log, and a synopsis of their research project with its anticipated impact on the literature of the field. The table of contents and resume are expected to evolve during the assembly of the final product. The students are entreated to make an attractive presentation in a 2-3 inch 3-ring binder with section tabs. The completed portfolio should paint a clear picture of who the student is with his/her unique accomplishments and characteristics and what the student can contribute to the physical therapy profession.

These students, too, have found the portfolio to be a valuable tool in the job-hunting process (Benitez, 2003, Wurdeman, 2002). Employers seem very please to review visual evidence of the student's accomplishments. This process triggers questions that can be further explored in the interview. Record keeping is an important part of a physical therapist's daily duties. Clinical notes are considered legal documents.
By reviewing the portfolio, a potential employer can form impressions of the care a student takes in writing and his/her organizational skills. Clinical performance evaluations give an overview of the student's patient care skills and history. The patient log provides evidence of the types of patients with whom the student is familiar. The portfolio condenses eight semesters of work and development into an easily reviewed document that highlights the students' academic and clinical accomplishments.

\section{Conclusion}

Portfolios have and will continue to evolve throughout the years. With ever-increasing technology, the digital format of the portfolio has now emerged (McKenzie, Cleary, McKenzie \& Stephen, 2002). Regardless of the format, the professional portfolio is an important instrument in documenting a health educator's competence and as a job-seeking tool to elucidate one's strengths and experiences.

\section{References}

Benitez, B. (2003). Making your portfolio. The University of Texas at El Paso. Lecture.

Cleary, M. J. (1993). Using portfolios to assess student performance in school health education. Journal of School Health, 69, 377-381.

Cleary, M. J., \& Birch, D. A. (1996). Using portfolios for assessment in the college personal health course. Journal of Health Education, 27(2), 92-96.

Cleary, M. J., \& Birch, D. A. (1997). How prospective school health educators can build a portfolio to communicate professional expertise. Journal of School Health, 67(6), 228-231.

Cottrell, R. R., Girvan, J. T., \& McKenzie, J. F. (2002). Principles and foundations of health promotion and education (2nd ed.). San Francisco: Benjamin Cummings.

Gaberson, K., \& Oermann, M. H. (1999). Clinical teaching strategies in nursing education. New York: Springer.

Grant, G. E., \& Huebner, T. A. (1998). The portfolio question: A powerful synthesis of the personal and professional. Teacher Education Quarterly, 25, 33-43.

McKenzie, J. F., Cleary, M. J., McKenzie, B. L., \& Stephen, C. E. (2002). E-portfolios: Their creation and use by pre-service health educator. International Electronic Journal of Health Education, 55, 79-83

Oermann, M. H.(2002). Developing a professional portfolio in nursing. Orthopaedic Nursing, 21(2), 7378.

Salend, S. J. (2001). Creating your own professional portfolio. Intervention in School and Clinic, 36(4), 195-201.

Waishwell, L., Morrow, M. J., Micke, M. M., \& Keyser, B. B. (1996). Utilization of the student portfolio to link professional preparation to the responsibilities and competencies of the entry level health educator. Journal of Health Education, 27(1), 4-12.

Wurdeman, V. (2002). Professional portfolio. The University of Texas at El Paso. Lecture. 


\author{
Author Information \\ Sharon E. Thompson, MPH, PhD, CHES* \\ Assistant Professor \\ Health Science Program \\ College of Health Sciences \\ The University of Texas at El Paso \\ 1101 North Campbell Street \\ El Paso, Texas 79902 \\ Ph. 915-747-7221 \\ Fax. 915-747-7207 \\ E-Mail: sthompson@utep.edu \\ Ronald F. Bybee, PT, DPT, OCS, Dip MDT \\ Assistant Professor \\ Physical Therapy Program \\ College of Health Sciences \\ The University of Texas at El Paso \\ * corresponding author
}

